\title{
The Assessment of COVID-19 Knowledge and Attitudes Among a Middle Eastern North African Community in Dearborn, Michigan
}

\author{
Malak A. Ismail ${ }^{1,2}$ (1) $\cdot$ Marwa Khalil $^{2,3} \cdot$ Roukaya Najdi $^{2,4} \cdot$ R. A. Blackwood ${ }^{2,5}$ \\ Accepted: 31 July 2021 / Published online: 28 August 2021 \\ (c) The Author(s), under exclusive licence to Springer Science+Business Media, LLC, part of Springer Nature 2021
}

\begin{abstract}
In 2020, COVID-19 was the third leading cause of death among individuals between the ages of 45-84 years (Woolf 325:123-124, 2021). However, systemic inequities and disparities exacerbated the pandemic's effect on racial and ethnic groups (Tai 72:703-706, 2021). The exact impact of the pandemic within the Middle Eastern North African (MENA) community is not well documented or understood due to the lack of federal recognition of MENAs as an ethnic group. Given the lack of COVID-19 research among this community, this study was created to address COVID-19 needs, perceptions, and health-seeking behaviors regarding COVID-19 precautions, mask wearing, and routine healthcare appointments. Between June and July 2020, an anonymous survey was distributed in English and Arabic using a Community Participatory Based Research design in Dearborn, Michigan. Overall, 298 individuals were surveyed and their misconceptions regarding COVID19 infections, spread, and precautions were identified. It is important to note that about $75 \%$ of survey respondents identified as female, while only $24 \%$ of survey participants identified as male. Survey participants slightly underestimated the distance in which COVID-19 can be transmitted as $5.5 \pm 3.5$. Participants severely underestimated COVID-19 deaths in the US, with $23 \%$ estimating that under 250,000 individuals would die from COVID-19. Overall, 60\% of participants reported that they did not have any difficulty adhering to COVID-19 precautions and self-quarantine rules during Ramadan, while this number dropped to only 36\% (87/238) after Ramadan. The goal of this study was to serve as a tool to better understand the misconceptions, difficulties, and needs regarding COVID-19 among this understudied population. The MENA community may be particularly vulnerable to the economic, medical, and social changes brought about by the COVID-19 pandemic.
\end{abstract}

Keywords COVID-19 $\cdot$ Survey $\cdot$ Pandemic $\cdot$ Middle Eastern $\cdot$ Michigan

\section{Introduction}

The novel coronavirus, COVID-19, has created a global health crisis leaving healthcare providers and public health professionals under-prepared and communities under-resourced.

Malak A. Ismail

ismailma@umich.edu

1 Health Behavior Health Education, School of Public Health, University of Michigan, Ann Arbor, USA

2 Office for Health Equity and Inclusion, University of Michigan Medical School, Ann Arbor, USA

3 Undergraduate School of Public Health, University of Michigan, Ann Arbor, USA

4 University of Michigan Dearborn, Dearborn, USA

5 Department of Pediatrics Infectious Diseases, University of Michigan Medical School, Ann Arbor, USA
After the first confirmed case of COVID-19 was reported in the state of Michigan, on March 10, 2020, cases have increased rapidly $[1,2]$. In particular, Wayne County has reported the highest number of confirmed cases within Michigan since the start of the pandemic and continues to increase into the fourth wave [3]. The city of Dearborn has been home to the highest concentration of Arabs outside of the Middle East for decades and has created a thriving cultural community [4]. The MENA American community is considered to be both an understudied and underreported population that lacks state level epidemiological data due to its lack of recognition as a formal federal racial category [5]. With the scarce literature on this community's health status, health needs, and health behaviors significant disparities persist, and health outcomes continue to deteriorate [6]. The combination of long withstanding health inequities and the current pandemic has left communities of color's health outcomes and health seeking behaviors dramatically altered $[7,8]$. The importance of sharing accurate 
information related to COVID-19 with communities can limit the spread of COVID-19, enhance public awareness, and improve the efficacy of future interventions within this community [9].

There is limited information available about community knowledge and attitudes toward COVID-19 and how health needs and health-seeking behaviors have changed. The MENA American community represent a niche population for assessing these variables due to their lack of existing organizational data, scarce medical literature assessing health-seeking behaviors, and diverse sociocultural background. This study is the first of its kind in assessing the impact of COVID-19 on health knowledge, needs, attitudes, and health-seeking behaviors within the MENA American community using a Community Based Participatory Research approach (CBPR).

\section{Theoretical Framework}

To optimize the relevance and translatability of our findings, the study was approached using a Community Based Participatory Research design (CBPR). To expand the scientific knowledge and literature on this community, the study actively worked with community members to collaboratively agree on decisions throughout every step of the research process [10]. The co-investigator and research assistants all identified as MENA Americans, spoke Arabic and are residents of the city of Dearborn. Our research team is comprised of community members of our target population that are able to understand the intricacies of MENA Americans. Since the study's inception, our team was able to collaborate with predominantly MENA American non-profit organizations, local schools, medical clinics, and businesses to study our own community.

In addition to CBPR, the study also applied cultural congruence to ensure that our study materials were culturally relevant and congruent with the community surveyed. It has been shown that cultural congruence of a research team allows for greater communication, predictability and trust among respondents $[11,12]$. This study did not test these constructs; however, cultural congruence conceptually allowed the research team to ask questions that may have been sensitive or personal in nature in relation to the impacts of COVID-19 has had physically, emotionally, and economically on respondents. The study team's cultural congruence encouraged participants to take part in the survey once research aims and community partners were presented.

\section{Methods}

After the study was determined to be exempt by the Institutional Review Board (IRBMED) at the University of Michigan Medical School, an anonymous, digital bilingual (English and Arabic) survey was created using a generalized survey service known as Qualtrics. The survey included 41 questions on demographics, COVID-19, and health-seeking behaviors. The demographics of respondents was determined through 15 questions asking about age, gender, race/ ethnicity, Arab country of origin, county location, immigration status, education and income levels. Afterwards, $(n=9)$ questions were adapted from Geldsetzer to rapidly assess community perceptions of infectious disease outbreaks [13]. To assess knowledge and attitudes a multi-scale item question was adapted from Zhong et al. to evaluate mask-wearing habits [14]. Through Goodman-Casanova et al. $(n=4)$ questions were used from to assess comorbidities and care engagement to determine changes in healthcare services due to the shift to telehealth [15]. To understand the psychological needs and impact of COVID-19 on this community, $(n=4)$ questions were adapted from Wang et al.'s study to assess factors associated with the immediate psychological response [16]. The remaining questions $(n=8)$ were created based on published health belief studies assessing the Arab American community [12].

The survey was distributed to individuals between the ages of 18-65 years, with a focus on MENA American identifying individuals within Wayne County, Michigan. Participants were recruited online through groups affiliated with University of Michigan, Wayne State University, and University of Michigan Dearborn. Research assistants also recruited participants using influential social media pages based on popularity and following from MENA American identifying individuals.

\section{Data Analysis}

Statistical analysis was conducted using descriptive statistics, ANOVA, Two Samples Independent T-Tests and Chi Squared.

\section{Results}

Data was collected from June 14 to July 24, 2020, with a total number of surveys collected as 298 . Table 1 characterizes the demographics of the respondents. The average age of respondents was $25.81 \pm 8$ years old. An overwhelming majority of participants, $75 \%(\mathrm{~N}=224 / 298)$ identified as female. Most, $80 \%(\mathrm{~N}=247 / 298)$ participants identified 
Table 1 Participant demographics

\begin{tabular}{|c|c|}
\hline Characteristic & Distribution \\
\hline Total Number of Participants & $\mathrm{N}=298$ \\
\hline Participant Gender & $\mathrm{N}=298$ \\
\hline Male & $72(24.16 \%)$ \\
\hline Female & $224(75.17 \%)$ \\
\hline Other & $2(0.67 \%)$ \\
\hline Participant Average Age & $\begin{array}{l}\mathrm{N}=273 \\
25.81 \pm 8.03\end{array}$ \\
\hline Participant Sexual Orientation & $N=294$ \\
\hline Heterosexual & $257(87.41 \%)$ \\
\hline Bisexual & $13(4.42 \%)$ \\
\hline Other & $15(5.10 \%)$ \\
\hline Prefer not to say & $6(2.04 \%)$ \\
\hline Gay & $2(0.68 \%)$ \\
\hline Lesbian & $1(0.34 \%)$ \\
\hline Participant Race \& Ethnicity & $\mathrm{N}=298$ \\
\hline Middle Eastern North African & $247(82.89 \%)$ \\
\hline Caucasian/White & $20(6.71 \%)$ \\
\hline Asian American & $14(4.69 \%)$ \\
\hline African American/Black & $2(0.67 \%)$ \\
\hline Multiracial & $11(3.69 \%)$ \\
\hline Other & $4(1.34 \%)$ \\
\hline Participant Country of Origin & $\mathrm{N}=265$ \\
\hline Lebanon & $149(56.23 \%)$ \\
\hline Iraq & $37(13.96 \%)$ \\
\hline Palestine & $23(8.68 \%)$ \\
\hline Yemen & $19(7.17 \%)$ \\
\hline Syria & $16(6.04 \%)$ \\
\hline Egypt & $8(3.02 \%)$ \\
\hline Jordan & $5(1.89 \%)$ \\
\hline Other & $5(1.89 \%)$ \\
\hline Kuwait & $2(0.75 \%)$ \\
\hline Morocco & $1(0.38 \%)$ \\
\hline Participant Religious Background & $\mathrm{N}=295$ \\
\hline Islam & $249(84.41 \%)$ \\
\hline Christianity & $18(6.10 \%)$ \\
\hline Agnostic & $5(1.69 \%)$ \\
\hline Atheism & $6(2.03 \%)$ \\
\hline Other & $10(3.39 \%)$ \\
\hline Prefer not to say & $7(2.37 \%)$ \\
\hline Participant Religiosity & $\mathrm{N}=292$ \\
\hline Very religious & $56(19.18 \%)$ \\
\hline Moderately religious & $143(48.97 \%)$ \\
\hline Somewhat religious & $56(19.18 \%)$ \\
\hline Not Religious & $28(9.59 \%)$ \\
\hline I prefer not to answer & $9(3.08 \%)$ \\
\hline Participant Residence & $\mathrm{N}=281$ \\
\hline Wayne County, MI & $231(82.21 \%)$ \\
\hline Oakland County, MI & $35(4.81 \%)$ \\
\hline Washtenaw County, MI & $26(3.58 \%)$ \\
\hline Macomb County, MI & $7(0.96 \%)$ \\
\hline
\end{tabular}

Table 1 (continued)

\begin{tabular}{ll}
\hline Characteristic & Distribution \\
\hline Other & $156(20.77 \%)$ \\
Participant Immigrant Status & $\mathrm{N}=298$ \\
Born in the US & $221(74.16 \%)$ \\
Immigrant & $48(16.11 \%)$ \\
Refugee & $11(3.69 \%)$ \\
Other & $13(4.36 \%)$ \\
Prefer not to say & $2(0.67 \%)$ \\
Lives in the Middle East & $2(0.67 \%)$ \\
Lives in North Africa & $1(0.34 \%)$ \\
Participant Education Status & $\mathrm{N}=280$ \\
Less than high school degree & $3(1.07 \%)$ \\
High school graduate & $43(15.36 \%)$ \\
Some college but no degree & $86(30.71 \%)$ \\
Associate degree in college $(2-y e a r)$ & $31(11.07 \%)$ \\
Bachelor's degree in college (4-year) & $74(26.43 \%)$ \\
Master's degree & $21(7.50 \%)$ \\
Doctorate degree & $3(1.07 \%)$ \\
Professional degree (JD, MD) & $13(4.64 \%)$ \\
Other & $6(2.14 \%)$ \\
Participant Household Income & $\mathrm{N}=277$ \\
Less than $\$ 20,000$ & $31(11.19 \%)$ \\
Between $\$ 20,000-\$ 49,000$ & $60(21.66 \%)$ \\
Between $\$ 50,000$ to $\$ 74,000$ & $47(16.97 \%)$ \\
Between $\$ 75,000$ to $\$ 99,000$ & $28(10.11 \%)$ \\
Between $\$ 100,000$ to $\$ 149,000$ & $45(16.25 \%)$ \\
Over $\$ 150,000$ & $36(13.00 \%)$ \\
I prefer not to say & $30(10.83 \%)$ \\
Employment Status & $\mathrm{N}=279$ \\
Employed & $101(36.20 \%)$ \\
Employed Reduced Hours & $20(7.17 \%)$ \\
Furloughed & $9(3.23 \%)$ \\
Unemployed & $61(21.86 \%)$ \\
Student & $78(27.96 \%)$ \\
Other & $10(3.59 \%)$ \\
\hline &
\end{tabular}

as Middle Eastern/North African and a significant portion, 56\% $(\mathrm{N}=149 / 265)$ identified as Lebanese. Additionally, $84 \%(\mathrm{~N}=249 / 295)$ identified as Muslim and about $49 \%$ $(\mathrm{N}=143 / 292)$ reported being moderately religious. The vast majority of participants, $82 \%(\mathrm{~N}=231 / 281)$ resided in Wayne County, MI. Most respondents, 74\% ( $\mathrm{N}=221 / 298)$ identified as being born in the US, however, about $20 \%$ (59/298) identified as being foreign-born. Additionally, 50\% ( $\mathrm{N}=142 / 280)$ participants identified as being completing at least an Associate's Degree. Overall, 56\% (N=156/277) of participants reported their household income as greater than $\$ 50,000$ annually. In terms of employment, 36\% $(\mathrm{N}=101 / 279)$ reported being employed while about $10 \%$ 
(29/279) of respondents reported COVID related changes to their employment hours.

Table 2 characterizes the participants' attitudes towards COVID-19 and social distancing practices. Overall, 76\% $(\mathrm{N}=181 / 238)$ of participants felt that their community had taken some precautions and was adhering to most self-quarantine rules, as opposed to the $16 \%$ (39/238) that expressed their community has taken all precautions and adhered to all guidelines. Additionally, this survey was distributed 1 week after the month of Ramadan that is observed by many Muslims within the MENA community. Overall, 60\% $(\mathrm{N}=145 / 239)$ of participants reported that they did not have any difficulty adhering to COVID-19 precautions and selfquarantine rules during Ramadan, while only 36\% (87/238) of participants reported not having difficulties in maintaining COVID-19 precautions and self-quarantine rules after Ramadan. When prompting participants to select the places in which they wear masks, participants primarily selected grocery stores $38 \%$, work $24 \%$, and parks $12 \%$. Overall, a majority of participants, $83 \%(\mathrm{~N}=178 / 214)$ reported that at the time of the State of Michigan Stay-at Home order in June-July that they would remain practicing social distancing.

Table 3 characterizes participants' COVID-19 related knowledge and perceptions. Participants estimated that on average the Coronavirus could be transmitted around $5.5 \pm 3.5$ feet away. When prompted to select what primary sources of COVID-19 information respondents primarily rely on to remain updated about the pandemic the social media accounts of healthcare professionals $23.93 \%$ (134/560) and the Center for Disease Control 23.04\% $(129 / 560)$ were the most frequently selected and were a close tie. Additionally, around 8\% (44/560) of respondents opted to not be updated about the pandemic. About 27\% $(\mathrm{N}=69 / 255)$ of participants estimated that by the end of 2020 there would be around 251,000 to 500,000 COVID19 related deaths. When prompted, 35\% $(\mathrm{N}=89 / 254)$ of participants estimated the portion of the US population to be infected with COVID-19 at the time of the survey as 20-49\%. Additionally, when asked to estimate the same

Table 2 Attitudes and social distancing

\begin{tabular}{|c|c|}
\hline Characteristic & Distribution \\
\hline Community Response to COVID-19 Precautions & $\mathrm{N}=238$ \\
\hline My community has taken all precautions and is adhering to all self-quarantine rules & $39(16.39 \%)$ \\
\hline My community has taken some precautions and is adhering to most self-quarantine rules & $181(76.05 \%)$ \\
\hline My community has taken no precautions and is not adhering to self-quarantine rules & $18(7.56 \%)$ \\
\hline Difficulty adhering to COVID-19 precautions during Ramadan & $\mathrm{N}=239$ \\
\hline No it has not been difficult. I have taken all precautions and I am adhering to all self-quarantine rules & $145(60.67 \%)$ \\
\hline It has been slightly difficult. I have taken some precautions and I am adhering to most self-quarantine rules & $66(27.62 \%)$ \\
\hline It has been very difficult. I have taken no precautions and I am not adhering to self-quarantine rules & $3(1.26 \%)$ \\
\hline Participants do not participate in Ramadan & $25(10.46 \%)$ \\
\hline Difficulty adhering to COVID-19 precautions $\underline{\text { after Ramadan }}$ & $\mathrm{N}=238$ \\
\hline No it has not been difficult. I have taken all precautions and I am adhering to all self-quarantine rules & $87(36.55 \%)$ \\
\hline It has been slightly difficult. I have taken some precautions and I am adhering to most self-quarantine rules & $120(50.42 \%)$ \\
\hline It has been very difficult. I have taken no precautions and I am not adhering to self-quarantine rules & $6(2.52 \%)$ \\
\hline Participants do not participate in Ramadan & $25(10.46 \%)$ \\
\hline Mask wearing in the following places (select all that apply) & Count $=602$ \\
\hline Grocery stores & $230(38.21 \%)$ \\
\hline Parks & $74(12.29 \%)$ \\
\hline Running/Walking outdoors & $37(6.15 \%)$ \\
\hline Work & $145(24.09 \%)$ \\
\hline Protests & $61(10.13 \%)$ \\
\hline Other & $32(5.32 \%)$ \\
\hline I only wear my mask in large gatherings & $23(3.82 \%)$ \\
\hline After the state Stay-at Home order is lifted will you continue to practice social distancing & $\mathrm{N}=214$ \\
\hline Definitely yes & $113(52.80 \%)$ \\
\hline Probably yes & $65(30.37 \%)$ \\
\hline Might or might not & $26(12.15 \%)$ \\
\hline Probably not & $9(4.21 \%)$ \\
\hline Definitely not & $1(0.47 \%)$ \\
\hline
\end{tabular}


Table 3 COVID-19 knowledge \& perceptions

\begin{tabular}{ll}
\hline Characteristic & Distribution \\
\hline COVID-19 Information Source & Count $=560$ \\
Center for Disease Control & $129(23.04 \%)$ \\
World Health Organization & $98(17.50 \%)$ \\
News Stations & $78(13.93 \%)$ \\
University/Educational Institution & $77(13.75 \%)$ \\
Social media accounts of Healthcare professionals & $134(23.93 \%)$ \\
Prefer not to be updated & $44(7.86 \%)$ \\
Participant estimation of COVID-19 related deaths & $\mathrm{N}=255$ \\
$1,001-10,000$ & $16(6.27 \%)$ \\
$10,001-100,000$ & $29(11.37 \%)$ \\
$100,001-250,000$ & $60(23.53 \%)$ \\
$251,000-500,000$ & $69(27.06 \%)$ \\
$500,001-1$ million & $47(18.43 \%)$ \\
Between 1 and 10 million & $29(11.37 \%)$ \\
Between 10 and 100 million & $4(1.57 \%)$ \\
Participant estimation of COVID-19 infections in US & $\mathrm{N}=254$ \\
Under 10\% & $54(21.26 \%)$ \\
$11-19 \%$ & $51(20.08 \%)$ \\
$20-49 \%$ & $89(35.04 \%)$ \\
$50-64 \%$ & $35(13.78 \%)$ \\
$65-75 \%$ & $17(6.69 \%)$ \\
$76-89 \%$ & $7(2.76 \%)$ \\
$90-95 \%$ & $1(0.39 \%)$ \\
Participant estimation of COVID-19 infections among & $\mathrm{N}=246$ \\
MENA Americans & \\
Under 5\% & $58(23.58 \%)$ \\
$6-10 \%$ & $56(22.76 \%)$ \\
$11-19 \%$ & $45(18.29 \%)$ \\
$20-49 \%$ & $58(23.58 \%)$ \\
$50-64 \%$ & $15(6.10 \%)$ \\
$65-75 \%$ & $7(2.85 \%)$ \\
$76-89 \%$ & $2.03 \%)$ \\
Participant Estimation of COVID transmission in feet & Avg $5.5 \pm 3.5$ \\
\hline
\end{tabular}

for MENA Americans, there was an exact tie with $23.58 \%$ $(\mathrm{N}=54 / 254)$ estimating under $10 \%$ and the other $23.58 \%$ of respondents estimating around $20-49 \%$ of the MENA American population.

Table 4 characterizes participants' current health status and changes in health behaviors. Most participants, $58 \%(\mathrm{~N}=138 / 238)$, reported that they did not to receive COVID-19 testing, $19 \%(\mathrm{~N}=45 / 238)$ of participants reported that they received testing and tested negative, while $8 \%(N=20 / 238)$ reported that they had not been able to receive testing. Overall, 67\% ( $\mathrm{N}=160 / 239)$ of participants reported that they knew someone who tested positive for COVID-19 and on average participants knew about 5 $(5.26 \pm 4.68)$ individuals who tested positive for COVID-19.
In terms of primary healthcare provider appointments, $41 \%$ ( $N=89 / 214)$ participants reported that they themselves canceled their appointment out of fear or their physician canceled the appointment out of precaution. Additionally, $34 \%$ (74/214) of participants had their appointments with physician specialists were canceled or postponed for similar reasons. Among respondents or members in their household, the primary medications that are currently being taken are for blood pressure (17.16\%), diabetes (13.94\%), and general pain medication (11.53\%). Finally, about $27 \%$ of participants felt that social isolation was negatively affecting their mental health.

\section{Discussion}

This study, which used a community-based participatory research (CBPR) approach, is a crucial first step in understanding MENA Americans' health needs, attitudes, and perceptions of COVID-19 during the COVID-19 pandemic. While the sampling design of the study relied on convenience sampling, the respondents, however, capture a niche MENA community in southeast Michigan. As presented in Table 1, this convenience sample was composed of a majority of young female adults that identified as MENA individuals which may have had an unintended influence in the survey results. Although this cohort does not represent all MENA Americans in the US, it does allow for a better understanding of COVID-19 within the MENA community in Wayne County, Michigan. The study collected data oneweek post-Ramadan, in which Muslims fast from sun-up to sun-down daily for 30 days. Participants reported a slight increase (Table 2) in difficulty adhering to self-quarantine rules and safety precautions after Ramadan.

In regard to COVID-19 beliefs and perceptions, Table 3 highlighted that respondents understood the general transmission of COVID-19, mask wearing, and COVID symptoms. Interestingly, participants selected both the social media accounts of healthcare professionals and the Center for Disease Control as the primary sources of COVID-19 related news and information. With the increase of false information during the pandemic, it is important that communities of color, including the MENA community, are represented in healthcare as representation and inclusion in medicine can allow for culturally relevant communication. It is also necessary to better understand this vulnerable community's health needs and address any misconceptions. Although our survey was not validated, participants were provided a range of questions about COVID-19 beliefs and social distancing practices and can help better understand trends among MENA Americans. As this community is largely understudied, understanding their health behaviors and COVID-19 perceptions can assist in addressing 
Table 4 Health status and health behaviors

\begin{tabular}{|c|c|}
\hline Characteristic & Distribution \\
\hline Have you been tested for COVID-19 & $\mathrm{N}=238$ \\
\hline Yes and tested negative & $45(18.91 \%)$ \\
\hline Yes and tested positive & $7(2.94 \%)$ \\
\hline Minor symptoms but did not get tested & $12(5.04 \%)$ \\
\hline Have not been able to receive testing & $20(8.40 \%)$ \\
\hline Afraid to get tested because of pain & $8(3.36 \%)$ \\
\hline Do not want to be tested & $8(3.36 \%)$ \\
\hline Do not need to be tested & $138(57.98 \%)$ \\
\hline Number of individuals participants know tested positive for COVID-19 & $\mathrm{N}=239$ \\
\hline Yes & $160(66.95 \%)$ \\
\hline No & $79(33.05 \%)$ \\
\hline Average number of individuals participants know tested positive & $5.26 \pm 4.68$ \\
\hline Postponed primary healthcare provider appointments & $\mathrm{N}=214$ \\
\hline Yes, feared COVID-19 infection & $48(22.43 \%)$ \\
\hline Yes, physician canceled out of precaution & $41(19.16 \%)$ \\
\hline No & $65(30.37 \%)$ \\
\hline Not Applicable & $55(25.70 \%)$ \\
\hline Postponed specialty physician appointments & $\mathrm{N}=214$ \\
\hline Yes, feared COVID-19 infection & $35(16.36 \%)$ \\
\hline Yes, physician canceled out of precaution & $39(18.22 \%)$ \\
\hline No & $70(32.71 \%)$ \\
\hline Not Applicable & $70(32.71 \%)$ \\
\hline Current medications participant or other household members are currently taking for & Count 373 \\
\hline Blood thinners & $27(7.24 \%)$ \\
\hline Blood pressure & $64(17.16 \%)$ \\
\hline Diabetes & $52(13.94 \%)$ \\
\hline Heart disease & $24(6.43 \%)$ \\
\hline Mental Health (anti-depressants) & $27(7.24 \%)$ \\
\hline Cancer therapies & $8(2.14 \%)$ \\
\hline Pain medication & $43(11.53 \%)$ \\
\hline Oxygen & $4(1.07 \%)$ \\
\hline Inhalers & $33(8.85 \%)$ \\
\hline Other & $13(3.49 \%)$ \\
\hline None/Does not apply & $78(20.91 \%)$ \\
\hline Social isolation having a negative effect on mental health & $\begin{array}{l}\mathrm{N}=214 \\
\text { Count } 448\end{array}$ \\
\hline Myself & $120(26.79 \%)$ \\
\hline My spouse/significant other & $19(4.24 \%)$ \\
\hline My children & $18(4.02 \%)$ \\
\hline My parents & $63(14.06 \%)$ \\
\hline My extended networks & $31(6.92 \%)$ \\
\hline My friends & $94(20.98 \%)$ \\
\hline My family & 103 (22.99\%) \\
\hline
\end{tabular}

misconceptions and false information regarding COVID-19. Additionally, Table 4 reflects participants' changes to their physical and mental health status and care. Overall, a majority of individuals knew someone who tested positive, while a vast majority of participants did not feel the need to be tested. This stark comparison could be a concern in limiting the spread of COVID-19.

Although the study achieved many of its objectives, there are a few limitations that should be considered. The MENA American community is widely under researched; thus, our study adapted an exploratory research design. Survey 
responses capture a niche community in Dearborn, Michigan, however it is important to note that this study is limited due to convenience sampling. Moreover, the majority of participant respondents identified as female, resulting in our data not being fully representative of the MENA community. This should be taken into consideration as the full depth of understanding about COVID-19 among young men may be less clear and remains an issue that needs to be addressed. Also, because participants were recruited via social media, this data may not be representative of those without a computer or internet access.

Further research is needed to better understand the unique effect of the COVID-19 pandemic on MENA individuals within Wayne County and throughout the US. With an increase in the cancellation of routine healthcare appointments and lack of COVID-19 testing within this community it is important healthcare providers and professionals work to mitigate these factors and address the MENA American community's needs.

\section{Future Directions}

Future studies will assess the preventative health behaviors of this community, current health status, and perceptions towards the COVID-19 vaccine.

Acknowledgements The study would like to extend a special thank you to our community collaborators, schools, and businesses that were vital partners in the recruitment of our participants. The study would also like to thank Adnan Ismail for the translation of the study and Tami Hart-Johnson for her contributions in survey design and data modeling.

Author Contributions All authors contributed to the study conception and design. Material preparation, data collection, and analysis were performed by MI, MK, and RN.

\section{Declarations}

Conflict of interest All authors on this manuscript have no conflicts of interest or financial disclosures to report.

Ethical Approval This research involves human participants and was deemed exempt by the University of Michigan Medical School Institutional Review Board.

\section{References}

1. Woolf, S. H., Chapman, D. A., \& Lee, J. H. (2021). COVID-19 as the leading cause of death in the United States. JAMA, 325(2), 123-124.

2. Michigan announces first presumptive positive cases of COVID19. Michigan Department of Health and Human Services. (2020, March 10). Retrieved from https://www.michigan.gov/coronavirus/0,9753,7-406-98158-521365--,00.html
3. Wayne County COVID-19 Dashboard. Wayne County Public Health Division. (2020, September 24). Retrieved from http:// wayne.maps.arcgis.com/apps/opsdashboard/index.html\#/d04ff f4645b140319fad972eb3740550

4. Bureau, U. C. (2018, July 31). Arab Households in the United States: 2006-2010. Retrieved from https://www.census.gov/libra ry/publications/2013/acs/acsbr10-20.html

5. Kayyali, R. (2013). US Census classifications and Arab Americans: Contestations and definitions of identity markers. Journal of Ethnic and Migration Studies, 39(8), 1299-1318.

6. Betancourt, J. R., Green, A. R., Carrillo, J. E., \& Park, E. R. (2005). Cultural competence and health care disparities: Key perspectives and trends. Health Affairs, 24(2), 499-505. https://doi. org/10.1377/hlthaff.24.2.499

7. van Dorn, A., Cooney, R. E., \& Sabin, M. L. (2020). COVID-19 exacerbating inequalities in the US. Lancet (London, England), 395(10232), 1243.

8. Tai, D. B. G., Shah, A., Doubeni, C. A., Sia, I. G., \& Wieland, M. L. (2021). The disproportionate impact of COVID-19 on racial and ethnic minorities in the United States. Clinical Infectious Diseases, 72(4), 703-706.

9. Chesser, A., Drassen Ham, A., \& Keene Woods, N. (2020). Assessment of COVID-19 knowledge among University students: Implications for future risk communication strategies. Health Education \& Behavior. https://doi.org/10.1177/1090198120 931420

10. Winterbauer, N. L., Bekemeier, B., VanRaemdonck, L., \& Hoover, A. G. (2016). Applying community-based participatory research partnership principles to public health practice-based research networks. SAGE Open, 6(4), 2158244016679211.

11. Edwards, J. R., \& Cable, D. M. (2009). The value of value congruence. Journal of Applied Psychology, 94(3), 654-677. https://doi. org/10.1037/a0014891

12. Dabaja, E., Dabaja, K., Ismail, M., Haidous, M., Hamka, A., Blackwood, R. A., et al. (2020). Pediatric Muslim Fasting Practices in Southeast Michigan: A Community Survey. Journal of Community Health. https://doi.org/10.1007/s10900-020-00788-X

13. Geldsetzer, P. (2020). Use of rapid online surveys to assess People's perceptions during infectious disease outbreaks: a crosssectional survey on COVID-19. Journal of Medical Internet Research, 22(4), e18790.

14. Zhong, B. L., Luo, W., Li, H. M., Zhang, Q. Q., Liu, X. G., Li, W. T., et al. (2020). Knowledge, attitudes, and practices towards COVID-19 among Chinese residents during the rapid rise period of the COVID-19 outbreak: A quick online cross-sectional survey. International Journal of Biological Sciences, 16(10), 1745.

15. Med, J. (2020). Telehealth home support during COVID-19 confinement: Survey study among community-dwelling older adults with mild cognitive impairment or mild dementia. Journal of Medical Internet Research, 22(5), e19434.

16. Wang, C., Pan, R., Wan, X., Tan, Y., Xu, L., Ho, C. S., et al. (2020). Immediate psychological responses and associated factors during the initial stage of the 2019 coronavirus disease (COVID19) epidemic among the general population in China. International Journal of Environmental Research and Public Health, 17(5), 1729.

Publisher's Note Springer Nature remains neutral with regard to jurisdictional claims in published maps and institutional affiliations. 